\title{
A REVIEW OF CLASS 4 SLENDER SECTION PROPERTIES CALCULATION FOR THIN-WALLED STEEL SECTIONS ACCORDING TO EC3
}

\author{
Chi-King Lee ${ }^{1, *}$ and Sing-Ping Chiew ${ }^{2}$ \\ ${ }^{1}$ School of Engineering and Information Technology, University of New South Wales Canberra, Australia \\ ${ }^{2}$ Singapore Institute of Technology, Dover Campus, Singapore \\ *(Corresponding author: E-mail: c.lee@adfa.edu.au)
}

\section{A B S T R A C T}

A review is given to the procedure suggested by the Eurocode 3 for the section properties calculations of thin-walled Class 4 slender stee sections consists of plate elements. Focus will be given to the effective width approach described in the Eurocode 3 . The essential steps for the effective width calculation for single plate element subjected to different direct stress distribution are first given. It is then followed by a study that compares the two different procedures, namely the full iteration procedure and the simplified procedure adopted by Eurocode 3 for Class 4 slender section properties calculation. Calculation examples are then given to demonstrate the calculation steps for both the full and the simplified approaches. Results of the calculation examples indicate that while the simplified procedure eliminates the tedious iteration steps and is much more convenient for manual calculation, the full iteration method in general will lead to less conservative effective area and section modulus and thus could result in more economical design in practice.
A R T I C LE H I S T ORY

$\begin{array}{ll}\text { Received: } & \text { 02 October } 2018 \\ \text { Revised: } & \text { 26 February } 2019 \\ \text { Accepted: } & \text { 03 June 2019 }\end{array}$

\section{K E Y W O R D S}

Class 4 Slender Sections;

Thin-walled steel sections;

Effective width method

Effective area and modulus

\section{Introduction}

In the design of steel structures, classification of steel section is fundamentally important as it determines many basic properties of the section as well as how the section resistances are calculated in many design guidelines [1-3]. In the Eurocode 3 (EC3) [1], the following four classes of section are defined.

Class 1 Plastic: Sections belong to this class can develop plastic hinge with large rotation capacity. No reduction of plastic moment capacity is needed in plastic analysis and design [1]. The sectional compressive and bending resistances of a Class 1 section are defined by the gross area $A_{\text {gross }}$ and the plastic modulus $W_{p l}$, respectively.

Class 2 Compact: Sections belong to this class can develop plastic hinge but with limited rotation capacity. While EC3 [1] does not allow this section class to be used in plastic analysis for design, the sectional compressive and bending resistances of a Class 2 section are again defined by the gross area $A_{\text {gross }}$ and the plastic modulus $W_{p l}$, respectively.

Class 3 Semi-compact: Sections belong to this class can only develop resistance up to the elastic limit so that only the extreme fiber stresses can reach the material yield strength. The sectional compressive and bending resistances of a Class 3 section are defined by the gross area $A_{\text {gross }}$ and the elastic modulus $W_{e l}$, respectively.

Class 4 Slender: A Class 4 section will develop local buckling before the extreme fiber stresses attaining yield and therefore parts of the compressive zone of the section will be ineffective. As a result, the sectional compressive and bending resistances of a Class 3 section are defined by the effective area $A_{\text {eff }}$ and the effective modulus $W_{\text {eff }}$, respectively.

The procedure to classify a given section is mainly governed by Table 5.2 of EC3 Part 1-1 [1]. It should be noted that the limiting width to thickness ratios (the term $c / t$ in Table 5.2 of [1]) for different classes are depended on the stress distributions of the section (hence the loadings applied to the section) as well as the strength of steel used via the parameter $\varepsilon=\left(235 / f_{y}\right)^{0.5}$. This implies that once the section is classified as a non-Class 4 section, since for a given value of $f_{y}$, $A_{\text {gross }}, W_{e l}$ and $W_{p l}$ are intrinsic geometrical properties of the cross-section, the section resistances will be independent of the applied loads. However, for a Class 4 section since the effective width of the compression part shall depend on its stress distribution [2,3], this implies that both $A_{\text {eff }}$ and $W_{\text {eff }}$ (thus the section resistances) are depended on the applied loads. It should be mentioned that due to such loading dependent nature of Class 4 sections, the section properties calculation steps for Class 4 sections are more complicated than those for Class 1 to 3 sections. The main objective of this study is to summarize the principles adopted by the EC3 for Class 4 section properties calculation. In particular, both the full iteration procedure and the simplified procedure recommended by the EC3 Part 1-1[1] and Part 1-5[2] for Class 4 section properties calculations are reviewed and discussed. In addition, a few practical calculation examples will also be provided to demonstrate the essential calculations steps and the differences between the simplified and the full iteration procedures. It will be shown that while the simplified procedure is much more suitable for manual calculation and does not require the ratio between the axial force and the bending moments applied for calculation, the full iteration procedure will produce less conservative values of $A_{\text {eff }}$ and $W_{\text {eff }}$ and therefore should be encouraged to use in practice.

\section{The EC3's "Effective width" method for section properties calculation}

\subsection{An overview}

It is well known that a side supported thin steel plate with aspect ratio $\alpha=a / b \geq 1$ (Fig. 1) subject to direct loading along in-plane direction tends to buckle at a stress level $\sigma_{c r}$ less than the yield stress $f_{y}[4,5]$. However, after $\sigma_{c r}$ is reached, resistance of the plate is not completely exhausted and it shall have sufficient post-buckling strength due to stress redistribution. The ultimate resistance of the plate will be reached after yielding occurred at the two supported sides and this will result in final a non-uniform stress distribution $\sigma_{a c t}<f_{y}$ (Fig. 2). This phenomenon is commonly known as "plate like buckling" $[4,5]$ and is most obvious for geometrical prefect elastic plate but less remarkable for a realistic imperfect inelastic plate. It is also well known that as the value of $\alpha$ reduces, the post-buckling resistance of the plate will diminish gradually and the $2 \mathrm{D}$ plate like buckling behaviour of the plate will change back to the $1 \mathrm{D}$ buckling behaviour like a column. Obviously, the non-uniform distribution of $\sigma_{a c t}$ is not ideal for design of thin plate subjected to direct stress. Hence, in EC3 Part 1-5 [2], two different design methods, namely the effective width method (Fig. 2b) and the effective stress (Fig. 2c) method are suggested. In short, both methods aim to employ uniform stress block for design. While the effective width method reduces the gross width to an appropriate effective width $b_{\text {eff }}=\rho b<b$ that subjected to the constant yield strength $f_{y}$ for design (Fig. 2b), the effective stress method maintains a uniform stress $\sigma_{\text {equ }}=\chi f_{y}<f_{y}$ along the whole width. The reduction factors $\rho$ and $\chi$ are calculated based on the principle of equivalent in-plane force such that

For the effective width method: $\int_{0}^{b} \sigma_{a c t} d x=b_{e f f} \cdot f_{y}=\rho b f_{y}$

For the effective stress method: $\int_{0}^{b} \sigma_{a c t} d x=b \cdot \sigma_{e q u}=b \chi f_{y}=\chi b f_{y}$

It is obvious that for a cross section consist of a single plate, the two methods are equivalent to each another such that (Fig. 2b and Fig. 2c) $\chi b f_{y}=\rho b f_{y}$ and $\chi=\rho$. However, for cross sections that consist of more than one plate element (e.g. an I section), the two methods are not equivalent to each another $[2,4]$ and the effective stress method are generally more conservative. 


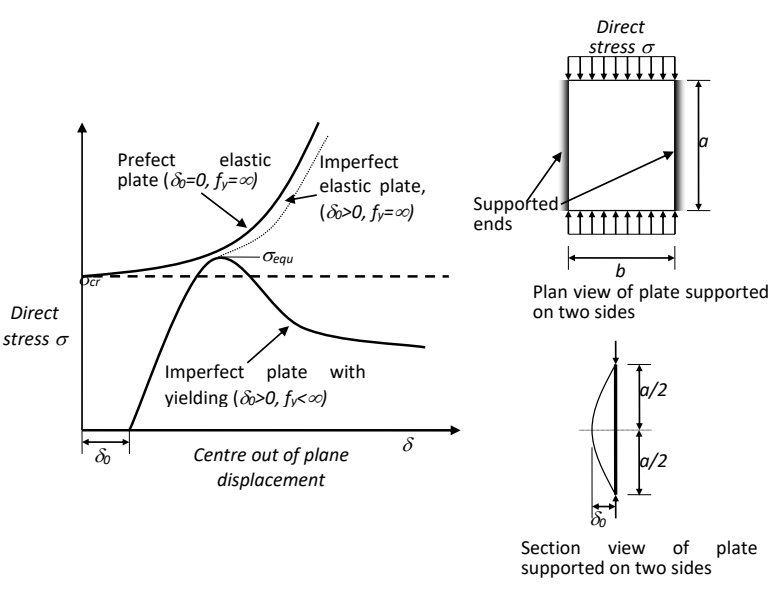

Fig. 1 Failure of plate with $\alpha=\mathrm{a} / \mathrm{b}>1$ subject to in-plane direct loading

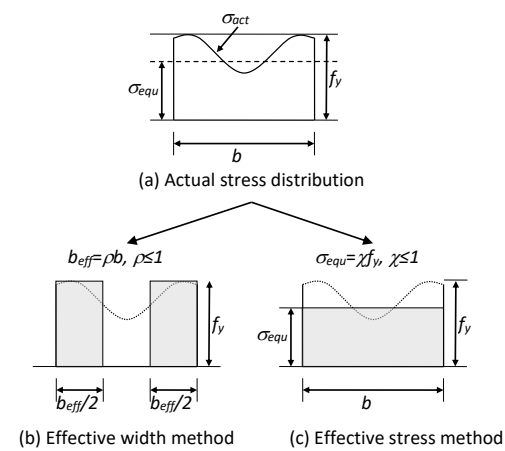

Fig. 2 Actual stress distribution at failure, effective width and stress methods

Table 1

Calculation of $k_{\sigma}$

\begin{tabular}{cc}
\hline \multicolumn{2}{c}{ Internal compression part (Fig. 3) } \\
\hline Range of $\psi$ & $k_{\sigma}$ \\
\hline$-3 \leq \psi<-1$ (Fig. 3c) & $5.98(1-\psi)^{2}$ \\
$-1 \leq \psi<0$ (Fig. 3c) & $7.81-6.29 \psi+9.78 \psi^{2}$ \\
$0 \leq \psi \leq 1$ (Figs. 3a and 3b) & $8.2 /(1.05+\psi)$ \\
\hline Outstand compression part with high stress \\
at supported ends (Figs. 4a and 4b) \\
\hline Range of $\psi$ & $k_{\sigma}$ \\
\hline$-1 \leq \psi<0$ (Fig. 4b) & $1.7-5 \psi+17.1 \psi^{2}$ \\
$1 \leq \psi \leq 0$ (Fig. 4a) & $0.578 /(\psi+0.34)$ \\
\hline Outstand compression part with lower stress \\
at supported ends (Figs. 4c and 4d) \\
\hline Range of $\psi$ & $k_{\sigma}$ \\
$1 \leq \psi<-3$ (Figs. 4c and 4d) & $0.57-0.21 \psi+0.07 \psi^{2}$ \\
\hline \multicolumn{2}{c}{}
\end{tabular}

It should be noted that EC Part 1-5 can be considered as largely "biased" towards the effective width method as Sections 4 to 7 (16 pages in length) of EC3 Part 1-5 were written based on this method while only Section 10 (2 pages in length) was devoted to describe the design approach if the effective stress method is employed. Hence, in the design of thin-walled structural components like plate girder and box section using EC3, the calculation of effective width of a Class 4 section is one of the most important steps during the section properties calculation [6-8].

\subsection{Effective width calculation}

In EC3 Part 1-5, for a given plate element (either supported on a single or on both sides) the effective width reduction factor $\rho$ is solely based on two parameters: (i) $\bar{b} / t$, the appropriate width $(\bar{b})$ to the plate thickness $(t)$ ratio of the element and (ii) the stress ratio at the two ends $\psi=\sigma_{2} / \sigma_{l}$ where $\sigma_{2}<\sigma_{l}$. In general, $\bar{b}$ is the appropriate clear width between the supports of the plate element. $\bar{b}$ is always slightly less than $b$, the overall width of the plate element, and should be calculated according to the section classification table (Table 5.2) of EC3 [1] and Section 4.4 of [2]. Figs. 3 and 4 respectively show the possible stress distributions for an internal compression element (i.e. the plate is supported at both ends) and an outstanding compression element (i.e. only one end of the plate is supported). Note that in Fig. 3 and Fig. 4, it is assumed that the stress distribution is linear and compressive stress is taken as positive. Furthermore, for $\psi<0$, the whole plate element is divided into two parts that are under tension and compression respectively with widths equal to $b_{t}$ and $b_{c}$, so that $\bar{b}=b_{t}+b_{c}$ and $b_{c}=\bar{b} /(1-\psi)$ (Fig. 3c, Fig. 4b and Fig. 4d). In general, the effective parts of the plate element consist of those parts that are either under tensile stress (i.e. the stress is negative) or those compressive parts that locate near the supported ends where local buckling is prevented to occur. Once the values of $\bar{b} / t$ and $\psi=\sigma_{2} / \sigma_{1}$ are known, the effective width of the plate element could be computed by using the following steps.

(1) Use the equations listed in Table 1 to calculate the buckling factor $k$ according to the stress ratio $\psi$ for different stress distributions shown in Fig. 3 and Fig. 4.

(2) Compute the plate slenderness ratio $\bar{\lambda}_{p}$ such that

$$
\bar{\lambda}_{p}=\frac{\bar{b} / t}{28.4 \varepsilon \sqrt{k_{\sigma}}}, \varepsilon=\sqrt{\frac{235}{f_{y}}}
$$

(3) Calculate the reduction factor $\rho$ for the compressive part of the element such that (EC3 Part 1-5, Equations. 4.2 and 4.3)

For an internal plate element (Fig. 3):

$\rho=\frac{\bar{\lambda}_{p}-0.055(3+\psi)}{\bar{\lambda}_{p}^{2}} \leq 1.0$ and $\bar{\lambda}_{p}>0.5+\sqrt{0.085-0.055 \psi}$

For an outstanding plate element (Fig. 4):

$\rho=\frac{\bar{\lambda}_{p}-0.188}{\bar{\lambda}_{p}^{2}} \leq 1.0$ and $\bar{\lambda}_{p}>0.784$

(4) Calculate $b_{\text {eff }}$, the effective width for the compressive part of the plate element, (Fig. 3 and Fig. 4)

For $\psi \geq 0: \quad b_{\text {eff }}=\rho \bar{b}$

For $\psi<0: \quad b_{e f f}=\frac{\rho \bar{b}}{(1-\psi)}=\rho b_{c}$

Note that for the case of an internal compression element with $\psi \geq 0$ (i.e. the whole plate element is under compression), the effective width of the element $b_{e f f}$ is further divided into two parts (Figs. 3(a) and 3(b)) with width $b_{e l}$ and $b_{e 2}$ such that $b_{e 1}+b_{e 2}=b_{e f f}$. The relative sizes of $b_{e l}$ and $b_{e 2}$ are defined in Fig. 3.

(5) Finally, the total effective width of the whole plate elements is computed as $b_{\text {eff }}$ (Fig. 3a, Fig. 4a and Fig. 4c) for $\psi \geq 0$ when the whole plate element is under compression or $b_{e f f}+b_{t}$ for $\psi<0$ when part of the plate element is under tension (Fig. 3c, Fig. 4b, and Fig. 4d).
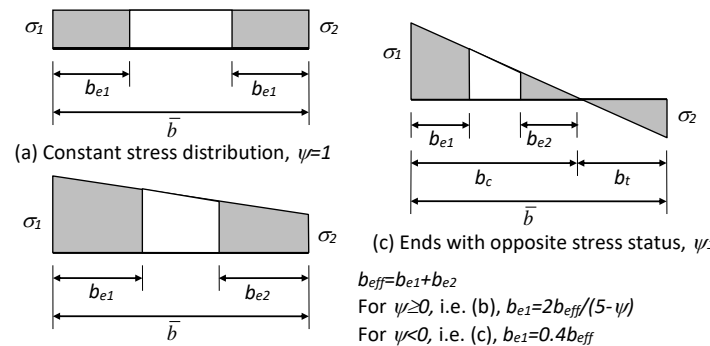

(b) Ends with same stress status, $1>\psi \geq 0$

(c) Ends with opposite stress status, $\psi \leq 0$ $b_{\text {eff }}=b_{e 1}+b_{e 2}$

For $\psi \geq 0$, i.e. (b), $b_{e 1}=2 b_{\text {eff }} /(5-\psi)$ For $\psi<0$, i.e. (c), $b_{e 1}=0.4 b_{e f f}$

Fig. 3 Stress distribution and effective width for internal compression elements (i.e. both end supported), effective part of the plate is shaded Note: Compressive stress is positive with $\sigma_{2}<\sigma_{l}$

Fig. 5 shows the plots of the ratio $\left(b_{e f f}+b_{t}\right) / \bar{b}$ against the stress ratio $\psi$ for a plate element with $f_{y}=355 \mathrm{MPa}$ and $\varepsilon=0.8136$ for different values of $\bar{b} / t$. From Fig. 5 , it is obvious that for any value of $\bar{b} / t$, the ratio $\left(b_{\text {eff }}+b_{t}\right) / \bar{b}$ always attends a minimum when $\psi=1$ when the plate element is subjected to uniform compression. It should be also noted from these figures that for $\psi=-1$ or when $b_{c}=b_{t}$ for the plate elements, there always exist a limiting value of $\bar{b} / t$ below which the plate element is fully effective (i.e. becomes a Class 3 section). For a plate with $f_{y}=355 \mathrm{MPa}$, these limiting values are corresponding to $\bar{b} / t=100$ for an internal element (Fig. 5a) and an outstanding element with compressive stress at supported end (Fig. $5 b$ ) and $\bar{b} / t=15.8$ for an outstanding element with tensile stress at supported end (Fig. $5 \mathrm{c}$ ). 

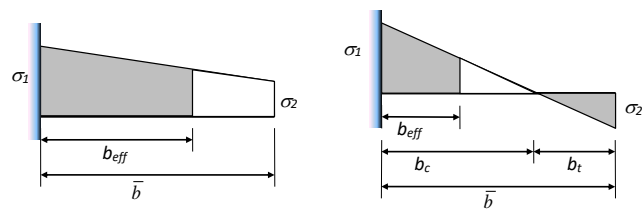

$\begin{array}{ll}\text { (a) Supported end with higher stress, } 1>\psi \geq 0 & \text { (b) Supported end with higher stress, } \psi<0\end{array}$

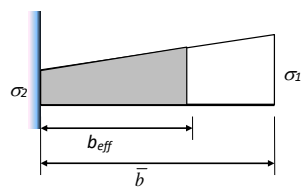

(c) Supported end with lower stress, $1 \geq \psi \geq 0$

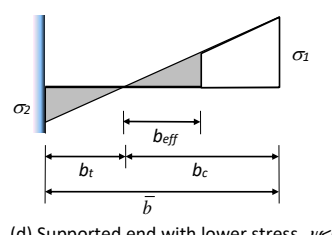

Fig. 4 Stress distribution and effective width for outstand compression elements (i.e. only end supported), effective part of the plate is shaded

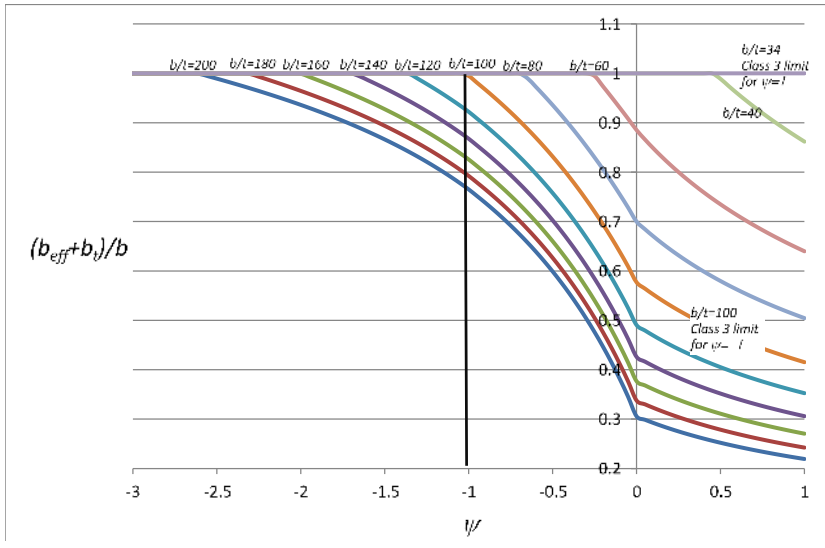

(a) Internal compression plate element (Fig. 3)

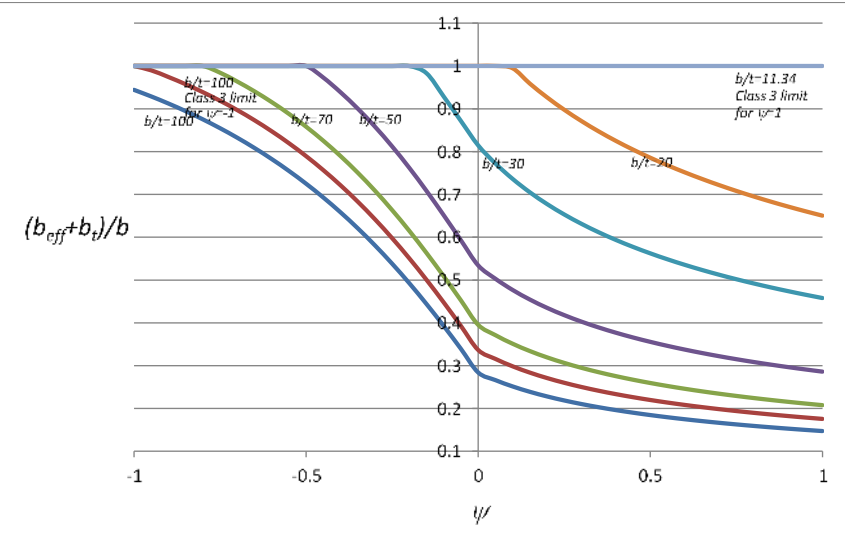

(b) Outstand plate element, support end with higher stress (Figs. 4a and 4b)

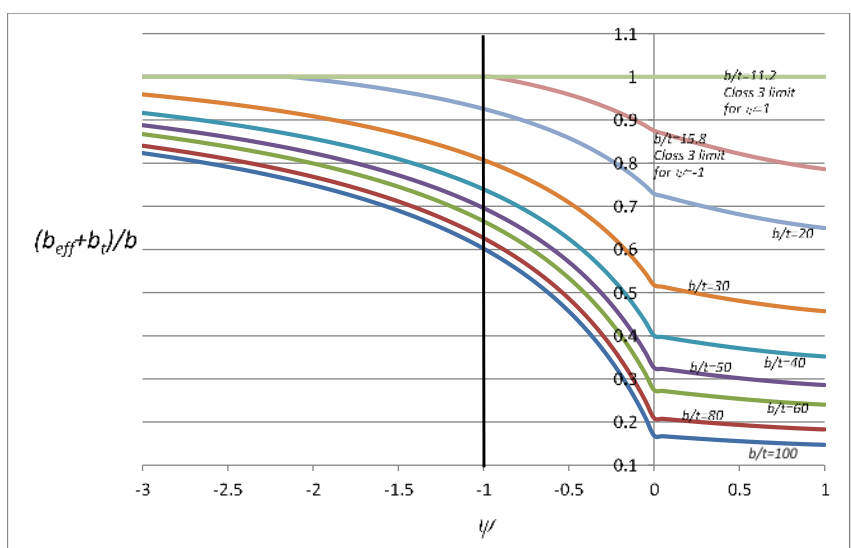

(c) Outstand plate element, support end with lower stress (Figs. 4c and 4d)

Fig. 5 Curves of $\left(b_{e f f}+b_{t}\right) / \bar{b}$ against $\psi$ for different values of $\bar{b} / t$ for a plate element with $f_{y}=355 \mathrm{MPa}$

\subsection{Alternative value of $\rho$ for stress level below the yield strength}

From Clauses 4.4(3) and E.1 of EC3 Part 1-5, if the maximum design compressive stress caused by all simultaneous actions is below the yield strength, the reduction factor $\rho$ for the compressive part of the element could be increased by first adjusting the factor $\bar{\lambda}_{p}$ defined in Equation 3 as

$\bar{\lambda}_{\mathrm{p}, \mathrm{red}}=\bar{\lambda}_{p} \sqrt{\frac{\sigma_{\mathrm{com}, \mathrm{Ed}}}{f_{y} / \gamma_{\mathrm{M} 0}}}$

In Equation $6, \sigma_{\text {com, red }}<f_{y}$ is the maximum design compressive stress in the element caused by all simultaneous actions, calculated by using the effective area of the section. After $\bar{\lambda}_{\text {pred }}$ is computed, the value of $\rho$ is then given by (c.f. Equation 4a)

$\rho=\frac{1-0.055(3+\psi) / \bar{\lambda}_{\mathrm{p}, \text { red }}}{\bar{\lambda}_{\mathrm{p}, \text { red }}}+0.18 \frac{\left(\bar{\lambda}_{p}-\bar{\lambda}_{\mathrm{p}, \text { red }}\right)}{\left(\bar{\lambda}_{p}-0.6\right)}$ but $\rho \leq 1$

Equations 6 and 7 will increase the value of $\rho$ but they require engineers to use the actual values of $N_{E d}$ and $M_{E d}$ for design. Furthermore, EC3 Part 1-1, Clause 5.2.2 (9) also allows one to increase the Class 3 width to thickness ratio limit if $\sigma_{c o m}$, red is used such that

$\varepsilon=\sqrt{\frac{f_{y}}{\sigma_{\text {com }, \text { red }}}} \sqrt{\frac{235}{f_{y}}}=\sqrt{\frac{235}{\sigma_{\text {com }, \text { red }}}}$

However, Equation 8 is not allowed to apply for buckling resistance calculation. Hence, in practice, while it could help to increase the section resistance (EC3 Part 1-1, 6.2.9.3), it will not able to increase the buckling strength of the member.

\section{Principle of section properties calculation by EC3}

As shown in Fig. 6a, a thin-walled steel section consists of a number of plate elements is subjected to the simultaneous actions of an axial loading $\left(N_{E d}\right)$ acting at the centroid of the gross section, $G_{\text {gross }}$ and the biaxial bending moments $M_{y, E d}$ and $M_{z, E d}$ respectively above the major axis y-y and the minor axis z-z of the gross section. For convenient, $G_{\text {gross }}$ is taken as the origin the $\mathrm{y}-\mathrm{z}$ coordinate system. It is assumed that at least one of the plate elements with $\bar{b} / t$ ratio exceeds the Class 3 limit so that some areas of the sections are ineffective and have to be removed during the cross-sectional properties calculation. According to EC3 $[2,4]$, in order to calculate the effective area of the whole section, it is first assumed that all the plate elements of the section could be separated into individual elements at their intersection points (Fig. 6b). After this, by assuming that the interaction points could provide sufficient end supports to the plate elements, effective areas of all plate elements will be obtained by considering the direct stress distribution within the elements. Finally, the section properties of the whole thin-walled section are obtained by recombining all plate elements together (Fig. 6c). As all ineffective areas are removed, the effective area of the section $A_{\text {eff }}$ is less than the section gross area $A_{\text {gross }}$. In addition, in general, there will be a shift in the position of the centroid $G_{\text {eff }}$ of the remaining effective area. Such shift in position can be generally expressed as $(\Delta y, \Delta z)$ with respect to the $y-z$ coordinate system. From elementary beam bending theory, the direct stress $\sigma(y, z)$ at a given point $(y, z)$ of the section can be expressed as (again compressive stress is taken as positive)

$\sigma(y, z)=\frac{N_{E d}}{A_{e f f}}+\frac{\left(M_{y, E d}+N_{E d} \Delta z\right)}{I_{y, e f f}(\Delta y, \Delta z)} y+\frac{\left(M_{z, E d}+N_{E d} \Delta y\right)}{I_{z, e f f}(\Delta y, \Delta z)} z$

In Equation 9, $I_{y, \text { eff }}$ and $I_{z, \text { eff }}$ are the effective second moment of area of the section about the $\mathrm{y}-\mathrm{y}$ and $\mathrm{z}-\mathrm{z}$ axes, respectively. $N_{E d} \Delta z$ and $N_{E d} \Delta y$ are additional moments generated due to the change of the location of the centroid of the effective area. Since all the plate elements of the section are straight elements, the direct stress within all plate elements will vary linearly. The method and equations described in Section 2 could be employed for the calculation of the effective areas of individual plate elements.

From Equation 6, it can be seen that if the section symmetrical above both the $y-y$ axis and the $z-z$ axis and is subjected to axial force only, one will have $\Delta z=\Delta y=0$ since any reduction in effective area will be symmetrical with respect to both the $y-y$ and $z-z$ axes. As a result, there shall be no shift of the location of $G_{\text {gross }}$ and the section properties of the effective areas could be calculated directly without any iteration. However, whenever the section is unsymmetrical or when bending moment is applied, due to the presence of the terms $N_{E d} \Delta z$ and $N_{E d} \Delta y$ and the fact that $I_{y, e f f}$ and $I_{z, e f f}$ are both functions of $(\Delta y, \Delta z)$, the stress ratio $\psi$ at the two ends of the plate will be depended on the location of $G_{e f f}$. Eventually, as the stress ratio $\psi$ itself also affects the effective area and eventually the 
location of $G_{e f f}$, the exact position of $G_{e f f}$ will not be expressed explicitly in simple analytical form and it could only be calculated iteratively [2, 4].

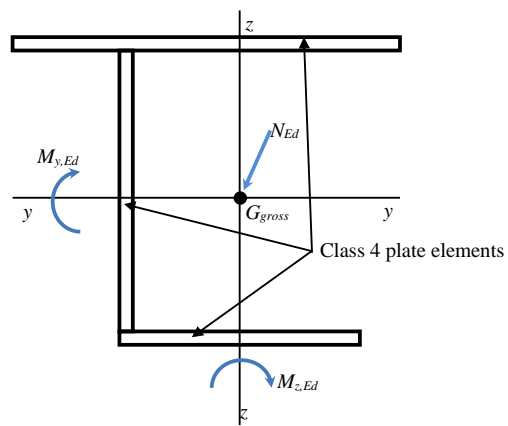

(a) A thin-walled section consists of class 4 plate elements under axial force $N_{E d}$ and biaxial bending moments $M_{y, E d}$ and $M_{z, E d}$

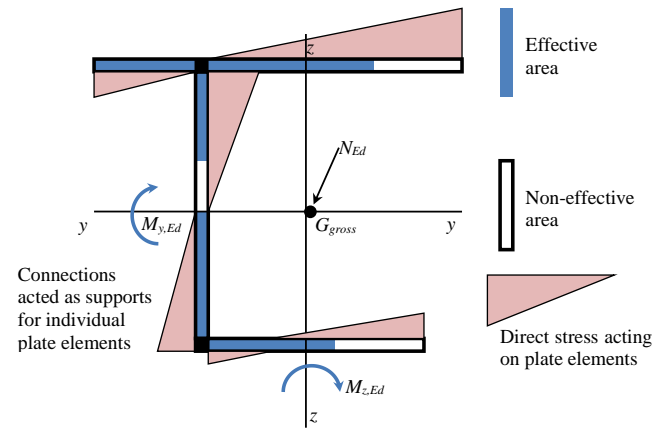

(b) Separation of the thin-walled section into individual plate elements

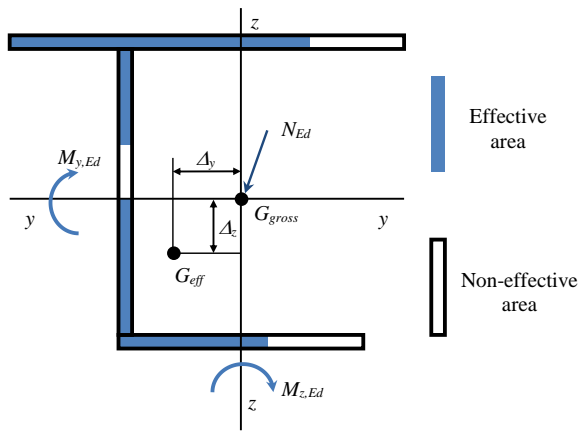

(c) Final effective section after combining individual plates

Fig. 6 Calculation of section properties of a Class 4 thin-walled section

\subsection{The full iteration and the simplified procedures}

As explained in the previous section and stated in Section 4.3 of EC3 Part 1-5 [2], an iterative procedure is generally required to compute the section properties of a Class 4 slender section. In this paper, such approach is referred as the full iteration procedure and the calculation steps are summarized in Box 1.

Box 1

Full iteration calculation procedure for class 4 section properties calculation

(1) By assuming the whole section is effective, calculate the gross section properties $\left(G_{\text {grosss }}, A_{\text {gross }}\right.$ and $\left.I_{\text {gross }}\right)$.

(2) Set $G_{\text {eff }}=G_{\text {gross }}, A_{\text {eff }}=A_{\text {gross }}, I_{\text {eff }}=I_{\text {gross }}$ and $\Delta y=\Delta z=0$

(3) Base on the current section properties, calculate the direct stress at end points of all the plate elements using Equation 9 and then compute the stress ratio $\psi$ for all plate elements.

(4) Base on the stress ratio $\psi$, determine the effective area of all plate elements by using Table 1, Equations. 3 to 5 and Fig. 3 and Fig. 4.

(5) Compute the new centroid of the effective area $G_{\text {eff }}$ ' and the corresponding effective area $A_{\text {eff' }}$ and effective second moment of area $I_{\text {eff }}$ '.

(6) Determine the shift of the centroid $G_{\text {eff }}-G_{\text {eff }}{ }^{\prime}=(\Delta y, \Delta z)$ and the relative change of effective area and effective second moment of area such that
$S_{G}(\%)=\frac{\sqrt{\Delta y^{2}+\Delta y^{2}}}{\min (b, h)} \times 100 \%$

$$
C_{A}(\%)=\frac{\left|A_{e f f}-A_{e f f^{\prime}}\right|}{A_{e f f}} \times 100 \% \text { and } C_{I}(\%)=\frac{\left|I_{e f f}-I_{e f f}\right|}{I_{e f f}} \times 100 \%
$$

where $b$ and $h$ in Equation 10a is the overall width and depth of the section.

(7) Update the section properties so that $G_{e f f} \leftarrow G_{\text {efff' }}, \mathrm{A}_{\text {efft }} \leftarrow A_{\text {eff }}$ ' and $I_{e f f} \leftarrow I_{\text {eff' }}$ '.

(8) Check for convergence of the section properties: The section properties are assumed to be converged if the following criteria are satisfied

$S_{G} \leq S_{t o l} \quad C_{A} \leq C_{A t o l} \quad C_{I} \leq C_{\text {Itol }}$

where $S_{t o l}, C_{A t o l}$ and $C_{\text {Itol }}$ are tolerances for the convergences of $G_{e f f}, A_{e f f}$ and $I_{\text {eff }}$, respectively.

(9) If the section properties are converged, output the value of $G_{\text {eff, }}, \mathrm{A}_{\text {eff }}$, and $I_{e f f}$ and stop. Otherwise, go to step (3)

Note that in in Section 4.3 of EC3 Part 1-5 [2], no recommendation is made on the convergence criteria of the full iteration procedure. Furthermore, Beg et al. [4] suggested that the iteration procedure should be stopped when the location of $G_{e f f}$ converged which is equivalent to adopting the first criterion of $S_{G} \leq S_{\text {tol }}$ in Equation 11. Since the axial and bending resistances of the section are largely depended on the values of $A_{\text {eff }}$ and $I_{\text {eff }}$, their values are also critical when conducting the section resistance check. Hence, it is suggested that a maximum value of $1 \%$ should be employed for the tolerance factors $S_{t o l}, C_{A t o l}$ and $C_{\text {Itol }}$ during practical calculations.

From Box 1, it can be seen that if full iteration procedure is used, repeat evaluations of Equations 3, 5 and 9 as well as calculations of the position of $G_{e f f}$ and the values of $A_{\text {eff }}$ and $I_{\text {eff }}$ are needed. Furthermore, it is shown in Appendix A that for an unsymmetrical section subject to axial force and biaxial bending, in order to elevate the new position of $G_{e f f}$, the ratios between the axial force and bending moments applied (i.e. $M_{y, E d} / N_{E d}$ and $M_{z, E d} / N_{E d}$ ) are required. For complex sections consist of many plate elements such calculations are tedious and are not convenient for manual calculation. Hence, in EC3 Part 1-5, two simplified procedures as summarized Box 2 are suggested to allow designer to calculate the effective area and section modulus manually.

Box 2

Simplified procedure for class 4 section properties calculation

Simplification 1

For I and box sections under bending moment only, only one iteration step of the full iteration procedure is required. That is, the first new position of centroid $G_{e f f}$ ' and $A_{\text {eff' }}$ and $I_{\text {eff' }}$ the section properties in Step (5) of Box 1 could be used for resistance check.

Simplification 2

When both axial force and bending moments are presents, $A_{\text {eff }}$ could be calculated by considering the stress ratio $\psi$ due to axial force only, while $I_{e f f}$ could be calculated by considering the stress ratio due to bending moment only. However, in both cases, the addition moment generated by the axial load due to the shift of centroid should be considered during resistance check.

It should be mentioned that in Simplification 2, while the calculation of $A_{\text {eff }}$ does not require any iteration, in general iterations are still required for the calculation of $I_{\text {eff. }}$ However, in case that the section under consideration is an I or a box section, Simplification 1 could be applied and only one iteration steps are needed to compute the value of $I_{\text {eff }}$. Furthermore, another important consequence of using the Simplification 2 is that as the ratio $\left(b_{e f f}+b_{t}\right) / \bar{b}$ always attends a minimum when $\psi=1$, the simplification will always lead to a smaller (and thus conservative) value of $A_{\text {eff }}$ when comparing with the full iteration procedure. However, it will be shown in the next section that, both Simplifications 1 and 2 will give a larger (and thus a non-conservative) value of $I_{\text {eff }}$.

\section{Section properties calculation examples}

In this section, five examples involving symmetrical I and square box sections are given to demonstrate how the simplified or the full iteration procedure could be employed to compute the section properties $\left(A_{e f f}\right.$ and $\left.I_{e f f}\right)$ of a Class 4 section. Loading cases involving pure axial force $\left(N_{E d}\right.$ only), pure bending $\left(M_{E d}\right.$ only) and both axial force and uniaxial bending moment above the major axis $\left(N_{E d}\right.$ and $\left.M_{E d}\right)$ are considered. In case that the full iteration procedure is employed, convergence of the solution is assumed if an accuracy of $C_{\text {Atol }}=C_{\text {Itol }}=0.1 \%$ (Equations. 10 and 11) is reached or at most up to four 
iterations are completed.

\subsection{Example 1: An I section under pure bending [4]}

In the first example, an I section with a Class 4 web and Class 1 flange (Fig. 7) under pure bending is employed as an example to demonstrate the calculation steps for effect section properties. The gross section properties of the section are given by:

$$
\begin{gathered}
h_{w}=1920 \mathrm{~mm}, t_{w}=10 \mathrm{~mm}, A_{\text {gross }}=51200 \mathrm{~mm}^{2}, \\
I_{\text {gross }}=3663530.67 \mathrm{~cm}^{4} \text { and } W_{e l}=37382.96 \mathrm{~cm}^{3}
\end{gathered}
$$

In this example, the actual value of $M_{E d}$ applied is immaterial as the stress ratio can be obtained by determining the location of the neutral axis. The detailed calculation steps for the first two iterations are shown in Box 3 and Fig. 8 .

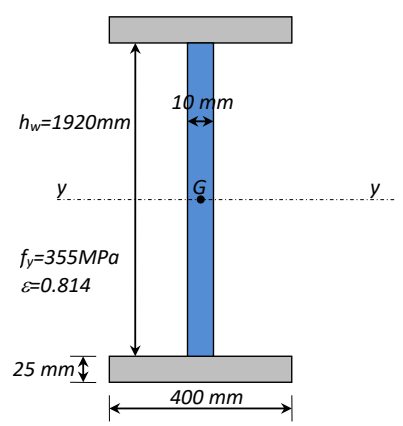

Fig. 7 Example 1: An I section under pure bending

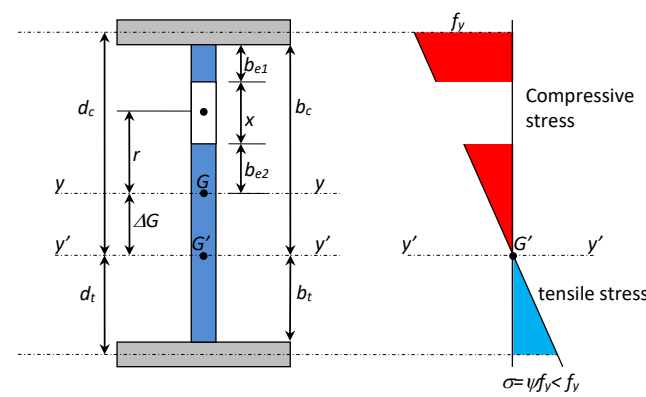

$G=$ Centroid of gross section $\quad G^{\prime}=$ Centroid of effective section

$\begin{array}{ll}\text { (a) Effective section (Class } 3 \text { equivalent) } & \text { (b) Stress distributions of }\end{array}$ equivalent Class 3 section (under sagging moment)

Fig. 8 Calculation of effective cross section

Box 3

Details calculation steps for iterations 1 and 2 for Example 1

$$
\begin{aligned}
& \text { First iteration } \\
& \text { Calculation of effective area, } A_{\text {eff }} \\
& \psi=-1 \text { (pure bending, fully effective section), } k_{\sigma}=23.9 \\
& \bar{\lambda}_{p}=\frac{h_{w} / \mathrm{t}_{w}}{28.4 \varepsilon \sqrt{k_{\sigma}}}=\frac{1920 / 10}{28.4 \times 0.814 \sqrt{23.9}}=1.699>1.08 \\
& \rho=\frac{\bar{\lambda}_{p}-0.055(3+\psi)}{\bar{\lambda}_{p}^{2}}=\frac{1.699-0.055(3-1)}{1.699^{2}}=0.550 \\
& b_{c}=1920 / 2=960 \mathrm{~mm}, b_{e f f}=0.55 \times 960=528 \mathrm{~mm}, \\
& b_{e I}=0.4 \times 528=211.2 \mathrm{~mm}, b_{e 2}=0.6 \times 528=316.8 \mathrm{~mm}, \\
& x=960-211.2-316.8=432 \mathrm{~mm}(\mathrm{Fig} .8) \\
& \text { Reduction of area: } \Delta A=10 \times 432=4320 \mathrm{~mm}{ }^{2} \\
& A_{e f f}=51200-4320=46880 \mathrm{~mm}^{2} \\
& C_{A}=8.44 \%>0.1 \%(\mathrm{Equation} 10 \mathrm{~b}) . \\
& \text { Calculation of } W_{\text {eff }} \\
& r=h_{w} / 2-b_{e l}-x / 2=1920 / 2+211.2-432 / 2=532.8 \mathrm{~mm} \\
& r \Delta A+A_{e f f} \Delta G=0 \text { or } \Delta G=-532.8 \times 4320 / 46880=-49.10 \mathrm{~mm}^{2} \\
& I_{\text {eff }}=I_{\text {gross }}+A(\Delta G)^{2}-\left(\frac{x^{3} t_{w}}{12}+\Delta A(r+\Delta G)^{2}\right) \\
& =\left(3663530.67 \times 10000+51200 \times 49.10^{2}-\left(\frac{432^{3} \times 10}{12}+\right.\right. \\
& \left.\left.4320(532.8+49.10)^{2}\right)\right) / 10000=3522877.067 \mathrm{~cm}^{4} \\
&
\end{aligned}
$$

$C_{I}=3.84 \%>0.1 \%$ (Equation 10b). $d_{c}=1000-20+49.10=1029.1 \mathrm{~mm}, d_{t}=1000$ $20-49.10=930.9 \mathrm{~mm}$

$W_{\text {eff }}=3522877.067 / 102.91=34232.60 \mathrm{~cm}^{3}$

Since both $C_{A}$ and $C_{I}>0.1 \%$, further iteration is carried out.

Second iteration

Calculation of effective area, $A_{\text {eff }}$

$\psi=-(960-49.1) /(960+49.1)=-0.903, k_{\sigma}=7.81-6.29 \psi+9.78 \psi^{2}=21.46$

$\bar{\lambda}_{p}=\frac{1920 / 10}{28.4 \times 0.814 \sqrt{21.46}}=1.793>1.08, \rho=\frac{1.793-0.055(3-0.903)}{1.793^{2}}=0.522$

$b_{c}=h_{w} / 2+\Delta G=1920 / 2+49.10=1009.1 \mathrm{~mm}, b_{\text {eff }}=0.522 \times 1009.1=526.8 \mathrm{~mm}$

$b_{e l}=0.4 \times 526.8=210.7 \mathrm{~mm}, b_{e 2}=0.6 \times 526.8=316.1 \mathrm{~mm}$

$x=b_{c}-b_{e l}-b_{e 2}=1009.1-210.7-316.1=482.3 \mathrm{~mm}$

Effective area reduction: $\Delta A=10 \times 482.3=4823 \mathrm{~mm}^{2}$ and $A_{\text {eff }}=51200$ $4823=46377 \mathrm{~mm}^{2}$

Hence, $C_{A}=1.07 \%>0.1 \%$ (Equation $10 \mathrm{~b}$ ).

Calculation of $W_{\text {eff }}$

$r=h_{w} / 2-b_{e 1}-x / 2=1920 / 2+210.7-482.3 / 2=508.15 \mathrm{~mm}$

$r \Delta A+A_{\text {eff }} \Delta G=0$ or $\Delta G=-508.15 \times 4823 / 46377=-52.84 \mathrm{~mm}$

This means that shift of $G^{\prime}$ to $G^{\prime \prime}=(-49.10-(-52.84))=3.74 \mathrm{~mm}$ (downward)

$I_{\text {eff }}=\left(3663530.67 \times 10000+51200 \times 52.84^{2}-\left(\frac{482.3^{3} \times 10}{12}+\right.\right.$

$\left.\left.4823(508.15+52.84)^{2}\right)\right) / 10000=3516692.4 \mathrm{~cm}^{4}$

$C_{l}=0.176 \%>0.1 \%, d_{c}=1000-20+52.84=1032.84 \mathrm{~mm}$

$d_{t}=1000-20-52.84=927.16 \mathrm{~mm}$

$W_{\text {eff }}=3516692.41 / 103.281=34049.76 \mathrm{~cm}^{3}$

Eventually, after the third iteration, $A_{e f f}=46338.5 \mathrm{~mm}^{2}, W_{\text {eff }}=34036.04 \mathrm{~cm}^{3}$ so that $C_{A}=0.08 \%$ and $C_{l}=0.01 \%$. The calculation results are summarized in Table 2. It can be seen that both $A_{\text {eff }}$ and $W_{\text {eff }}$ essentially converged after the first iteration and this justifies the simplify approach suggested in EC2 (Box 2).

Table 2

Summary of Example 1

\begin{tabular}{cccccc}
\hline Iteration & $A_{\text {eff }}\left(\mathrm{mm}^{2}\right)$ & $I_{\text {eff }}\left(\mathrm{cm}^{4}\right)$ & $W_{\text {eff }}\left(\mathrm{cm}^{3}\right)$ & $\Delta G(\mathrm{~mm})$ & $\psi$ \\
\hline 0 (Gross) & 51200 & 3663530.67 & 37382.96 & --- & -1.0 \\
1 & 46880 & 3522877.07 & 34232.60 & 49.10 & -0.903 \\
2 & 46377 & 3516692.40 & 34049.76 & 52.84 & -0.8960 \\
3 (Full) & 46385 & 3516296.83 & 34036.04 & 53.11 & -0.8952 \\
Simplified & 46880 & 3522877.07 & 34232.60 & 49.10 & -0.903 \\
\hline Full/Simplified & 0.99 & 0.99 & 0.99 & --- & --- \\
\hline
\end{tabular}

\subsection{Example 2: A class 4 square box section under pure compression}

In this example, a class 4 square box section under pure compression is considered (Fig. 9). The gross section properties of the section are given by

$$
\begin{gathered}
b_{f l}=1000 \mathrm{~mm}, t_{f}=t_{w}=10 \mathrm{~mm}, h_{w}=980 \mathrm{~mm}, A_{\text {gross }}=39600 \mathrm{~mm}^{2} \\
I_{\text {gross }}=646932 \mathrm{~cm}^{4}, W_{\text {el, gross }}=13069.33 \mathrm{~cm}^{3} .
\end{gathered}
$$

Under pure compression, both the flanges and webs are Class 4 with their central parts become non-effective (Fig. 10). However, as the section is doubly symmetric, the non-effective parts at the centre of each side do not change the location of the centroid and will not generate any additional moment. Hence, no iteration is needed to calculate $A_{\text {eff }}$ as shown in Box 4. Obviously, in this example, the actual value of $N_{E d}$ applied is immaterial.

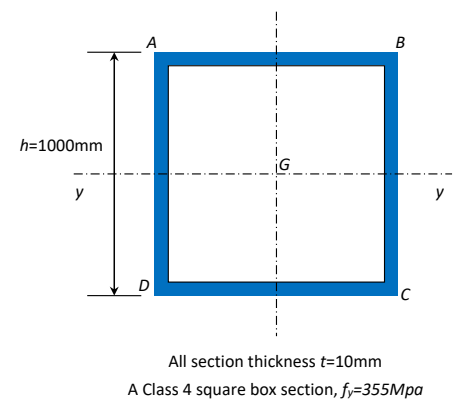

Fig. 9 Example 2: A class 4 square section under pure compression 


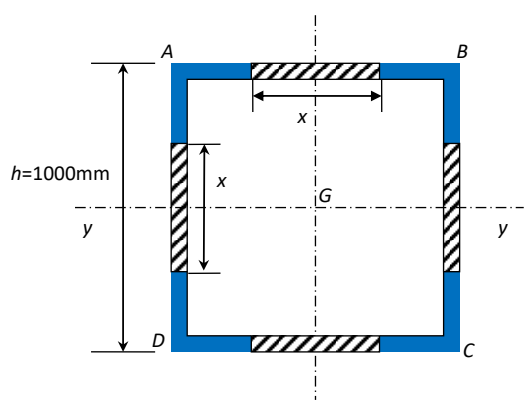

Fig. 10 Effective cross section of Example 2

\section{Box 4}

Calculation of $A_{\text {eff }}$ for Example 2

Calculation of $A_{\text {eff }}$ under pure axial compression

For the two flanges and the two webs $\psi=1$ (pure axial compression), $k_{\sigma}=4$

$\bar{\lambda}_{p}=\frac{b_{\mathrm{fl}} / \mathrm{t}_{\mathrm{fl}}}{28.4 \varepsilon \sqrt{k_{\sigma}}}=\frac{980 / 10}{28.4 \times 0.814 \sqrt{4}}=2.12$

$\rho=\frac{\bar{\lambda}_{p}-0.055(3+\psi)}{\bar{\lambda}_{p}^{2}}=\frac{2.12-0.055(3+1)}{2.12^{2}}=0.423$

$b_{\text {eff }}=0.423 \times 980=414.5 \mathrm{~mm}$,

$b_{e l}=0.5 \times 414.5=207.25 \mathrm{~mm}$,

$b_{e 2}=0.5 \times 414.5=207.25 \mathrm{~mm}$

$x=980-414.5=565.5 \mathrm{~mm}$

Hence, $A_{\text {eff }}=39600-4 \times(10 \times 565.5)=16980 \mathrm{~mm}^{2}$

$A_{\text {eff }} / A_{\text {gross }}=16980 / 39600=42.9 \%$.

\subsection{Example 3: A class 4 square box section under pure bending}

In this example, the square box section employed in Example 2 is considered again but now it is subject to pure bending so that the top flange $A B$ is under compression while the bottom flange $\mathrm{CD}$ is under tension and is fully effective (Fig. 11). There is a shift of the centroid from $G$ to $G^{\prime}$. For the webs, their classifications shall depend on the stress ratio at the top and bottom extreme fibres. The distance between $G$ and $G^{\prime}$ shall depend on whether the webs remain Class 3 or 4 after the new stress ratio of the webs is taken into account. For a box section under pure bending, Simplification 1 allows the designer to use one iteration to calculate $W_{\text {eff. }}$ Box 5 summarizes the calculation steps.

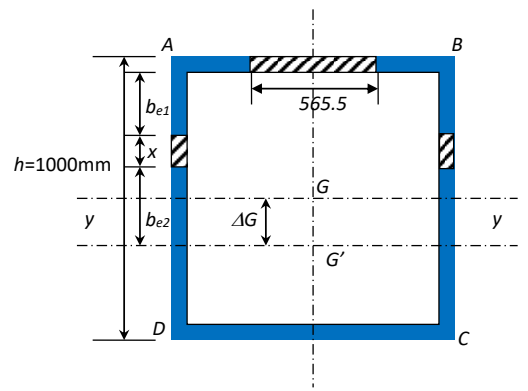

Fig. 11 Examples 3 and 4 with flange $C D$ under tension

Box 5

Calculation of $W_{\text {eff }}$ for Example 3

Calculation of $A_{\text {eff }}$ by assuming only the top flange $C D$ is class 4

For the flange $\mathrm{AB}$, same as Example 2:

$b_{e f f}=414.5 \mathrm{~mm}, b_{e l}=207.25 \mathrm{~mm}, b_{e 2}=207.25 \mathrm{~mm}, x_{l}=565.5 \mathrm{~mm}$,

$A_{\text {eff }}=A_{\text {gross }}-565.5 \times 10=33945 \mathrm{~mm}^{2}$

Hence, $r=500-5=495 \mathrm{~mm}, \Delta G=-495 \times 5655 / 33945=-82.46 \mathrm{~mm}$.

Recheck for Class 3 limit for the two webs

$\psi=-(980 / 2-82.46) /(980 / 2+82.46)=-0.712$

Hence, $42 \varepsilon /\left(0.67+0.33 \psi_{l}\right)=78.59<h_{w} / t_{w}=98$

The two webs shall become Class 4 .

First iteration

$\psi=-0.712, k_{\sigma}=7.81-6.29 \psi+9.78 \psi^{2}=17.25$.

For the two flanges: $\bar{\lambda}_{p}=1.021, \rho=0.859$

$b_{\text {eff }}=0.859 \times(980 / 2+82.46)=491.74 \mathrm{~mm}$ $b_{e l}=0.4 \times 491.74=196.70 \mathrm{~mm}, b_{e 2}=0.6 \times 491.54=295.04 \mathrm{~mm}$,

$x=980 / 2+82.46-491.74=80.72 \mathrm{~mm}$.

$A_{\text {eff }}=A_{\text {gross }}-565.5 \times 10-2 \times 10 \times 80.72=32330.6 \mathrm{~mm}^{2}$

$A_{\text {eff }} / A_{\text {gross }}=32330.6 / 39600=81.64 \%$

(Note: This $A_{\text {eff }}$ should only be used if the section is under pure bending only)

Calculation of $W_{\text {eff }}$

New position of $G$ ' after considering the webs are Class 4

$\Delta G^{\prime}=-(495 \times 5650+80.72 \times 10 \times 2 \times(980 / 2-196.70-80.72 / 2)) / 32330.6=$

$-99.21 \mathrm{~mm}$

$I_{\text {eff }}=\left(646932 \times 10000+39600 \times 99.21^{2}-\left(\frac{10^{3} \times 565.5}{12}+5655 \times\right.\right.$

$\left.(5+980 / 2+99.21)^{2}\right)-2 \times\left(\frac{80.72^{3} \times 10}{12}+80.72 \times 10 \times(99.21+980 / 2-\right.$

$\left.\left.196.70-80.72 / 2)^{2}\right)\right) / 10000=466126.44 \mathrm{~cm}^{4}$

$d_{c}=1000 / 2-5+99.21=594.21 \mathrm{~mm}, W_{e f f}=7844.47 \mathrm{~cm}^{3}$

$W_{\text {eff }} / W_{\text {gross }}=7844.47 / 13069.33=60 \%$

4.4. Example 4: A class 4 square box section under axial compression and bending

In this example, the same square box section used in Examples 2 and 3 is reconsidered again but now it is subjected to both axial compression and bending above the $y-y$ axis. In this case, if the Simplification 2 is used, one could determine $A_{\text {eff }}$ based on the compression force only (Example 2) and $W_{\text {eff }}$ based moment only (Example 3) so that $A_{\text {eff }}=16980 \mathrm{~mm}^{2}$ and $W_{\text {eff }}=7844.47 \mathrm{~cm}^{3}$.

However, in full iteration method, the stress ratio (and hence the classification) of the web shall depend on the magnitude of the compressive force and the bending moment. Under some loading conditions, it is possible that the web will remain as Class $3 / 4$ but the bottom flange will be Class 4 as the compressive force may be large enough to make the bottom flange under compression. In this case, in order to compute the section properties, it is necessary to know the values of $N_{E d}$ and $M_{E d}$ (or their ratio, as shown in Appendix A). In this example, it is assumed that $N_{E d}=3500 \mathrm{kN}$ and $M_{E d}=800 \mathrm{kNm}$ so that the flange $\mathrm{CD}$ will be under compression. Similar to the previous example, calculation is started by assuming that the section is fully effective first so that $A_{\text {gross }}=39600 \mathrm{~mm}^{2}, I_{\text {gross }}=646932 \mathrm{~cm}^{4}$ and $W_{\text {el, gross }}=13069.33 \mathrm{~cm}^{3}$. Box 6 shows the first two iteration steps and eventually three iterations are carried out to achieve convergence. Table 3 summarizes the results obtained from the full and simplified procedures. Regarding the adequacy of the Section, for the simplified method, from Equation 9, the maximum resultant stress is given by $\sigma_{\max }=3500 \times 1000 /(16980)+800 \times 1000 \times 1000 /(7844.47 \times 1000)$

$=308.14 \mathrm{MPa}<355 \mathrm{MPa}$

while based on full iteration

$\sigma_{\max }=3500 \times 1000 /(19054.4)+800 \times 1000 \times 1000 /(6821.53 \times 1000)$

$=300.7 \mathrm{MPa}<355 \mathrm{MPa}$

Hence, while the simplified method overestimated $W_{\text {eff }}$, it underestimated $A_{\text {eff }}$ a lot but it is still conservative in term of section resistance calculation.

Table 3

Summary of Example 4

\begin{tabular}{cccccc} 
Iteration & $A_{\text {eff }}\left(\mathrm{mm}^{2}\right)$ & $I_{\text {eff }}\left(\mathrm{cm}^{4}\right)$ & $W_{\text {eff }}\left(\mathrm{cm}^{3}\right)$ & $\Delta G(\mathrm{~cm})$ & $\psi$ \\
0 (Gross) & 39600 & 646932 & 13069.33 & --- & -1.0 \\
1 & 19313.2 & 352077.57 & 6824.93 & 20.87 & 0.186 \\
2 & 19058.4 & 351119.10 & 6820.50 & 19.80 & 0.251 \\
3 (Full) & 19054.4 & 351118.02 & 6821.53 & 19.72 & 0.255 \\
Simplified & $16980^{*}$ & $466126.44^{\wedge}$ & $7844.47^{\wedge}$ & $99.21^{\wedge}$ & $-0.712^{\wedge}$ \\
\hline Full/Simplified & 1.12 & 0.75 & 0.87 & --- & --- \\
\hline
\end{tabular}

*By considering $N_{E d}$ only, ${ }^{\wedge}$ By considering $M_{E d}$ only

Box 6

Detailed calculation steps of first two iterations for Example 4

\section{1st iteration}

Initial stress (assuming section is fully effective)

Stress at top of webs:

$3500 \times 1000 / 39600+800 \times 1000 \times 1000 \times 490 / 646932 \times 10000=148.98 \mathrm{MPa}$

Stress at bottom of webs:

$3500 \times 1000 / 39600-800 \times 1000 \times 1000 \times 490 / 646932 \times 10000=27.79 \mathrm{MPa}$

Since both flanges are under compression, they are Class 4 elements.

Effective width of top and bottom flanges (From Example 2)

$b_{e f f}=0.423 \times 980=414.5 \mathrm{~mm}, b_{e l}=0.5 \times 414.5=207.25 \mathrm{~mm}$

$b_{e 2}=0.5 \times 414.5=207.25 \mathrm{~mm}$ 
Effective width and areas of webs and section effective area $\psi=27.79 / 148.98=0.186$

Hence, $42 \varepsilon /(0.67+0.33 \psi)=46.74<h_{w} / t_{w}=98$ and the webs are Class 4 .

Stress ratio: $\psi=0.186, k_{\sigma}=8.2 /(1.05+\psi)=6.63, \bar{\lambda}_{p}=1.646, \rho=0.542$ $b_{e f f}=0.542 \times 980=531.16 \mathrm{~mm}, b_{e l}=2 b_{e f f} f(5-\psi)=220.67 \mathrm{~mm}$,

$b_{e 2}=b_{e f f}-b_{e 1}=310.49 \mathrm{~mm}$

$x=980-531.16=448.84 \mathrm{~mm}$.

Hence, $A_{\text {eff }}=A_{\text {gross }}-565.5 \times 10 \times 2-2 \times 10 \times 448.84=19313.2 \mathrm{~mm}^{2}$

$I_{\text {eff }}$ and $W_{\text {eff }}$ calculations

Shift of centroid $\Delta G=-(448.84 \times 10 \times 2 \times(980 / 2-220.67-448.84 / 2)) / 19313.2$ $=-20.87 \mathrm{~mm}$

$I_{\text {eff }}=352077.57 \mathrm{~cm}^{4}, W_{\text {eff }}=352077.57 \times 10 /(490+20.87+5)=6824.93 \mathrm{~cm}^{3}$

Updated stress at webs

Compressive stress due to axial force: $3500 \times 1000 / 19313.2=181.22 \mathrm{MPa}$

Bending stress at top of webs:

$800 \times 1000 \times 1000 \times(490+20.87) /(352077.57 \times 10000)=116.08 \mathrm{MPa}$

Bending stress at bottom of webs:

$800 \times 1000 \times 1000 \times(490-20.87) /(352077.57 \times 10000)=106.6 \mathrm{MPa}$

Total stress at top of webs: $181.22+116.08=297.3 \mathrm{MPa}$ (compression)

Total stress at bottom of webs: $181.22-106.6=74.62 \mathrm{MPa}$ (compression)

\section{2nd iteration}

New stress ratio: $\psi=74.62 / 297.3=0.251$

Effective width for webs and new $A_{\text {eff }}$

$k_{\sigma}=8.2 /(1.05+\psi)=6.303, \bar{\lambda}_{p}=1.689, \rho=0.529$

$b_{e f f}=0.529 \times 980=518.42 \mathrm{~mm}, b_{e l}=2 b_{e f f} /(5-\psi)=218.33 \mathrm{~mm}$,

$b_{e 2}=b_{e f f}-b_{e 1}=300.09 \mathrm{~mm}$

$x=980-518.42=461.58 \mathrm{~mm}$.

$A_{\text {eff }}=A_{\text {gross }}-565.5 \times 10 \times 2-2 \times 10 \times 461.58=19058.4 \mathrm{~mm}^{2}$

$I_{\text {eff }}$ and $W_{\text {eff }}$ calculations

Shift of centroid $\Delta G=-19.80 \mathrm{~mm}$. I.e. $\Delta G^{\prime}-\Delta G^{\prime \prime}=20.87-19.80 \mathrm{~mm}=1.07 \mathrm{~mm}$ (upward)

$I_{\text {eff }}=351119.10 \mathrm{~cm}^{4}, W_{\text {eff }}=351119.10 \times 10 /(490+19.80+5)=6820.5 \mathrm{~cm}^{3}$

Updated stress at webs

Compressive stress due to axial force: $3500 \times 1000 / 19058.4=183.65 \mathrm{MPa}$

Bending stress at top of webs:

$800 \times 1000 \times 1000 \times(490+19.80) /(351119.10 \times 10000)=116.15 \mathrm{MPa}$

Bending stress at bottom of webs:

$800 \times 1000 \times 1000 \times(490-19.80) /(351119.10 \times 10000)=107.13 \mathrm{MPa}$

Total stress at top of webs: $183.65+116.15=299.8 \mathrm{MPa}$ (compression)

Total stress at bottom of webs: $183.65-107.13=76.52 \mathrm{MPa}$ (compression)

The new stress ratio for next iteration is $\psi=76.52 / 299.8=0.255$

4.5. Example 5: A class 4 square box section under axial compression and bending with bottom flanges under tension

In the last example, the same square box section used in Example 4 is subjected to a lower axial compression of $N_{E d}=1000 \mathrm{kN}$ but a larger $M_{E d}=2000 \mathrm{kNm}$ so that flange CD is eventually under tension and four iterations are conducted. Detailed calculations for the first two iterations are shown in Box 7 and all iterations results are summarized in Table 4 . Regarding the adequacy of the section, based, for the simplified method, the maximum resultant stress of the section is given by

$\sigma_{\max }=1000 \times 1000 /(16980)+2000 \times 1000 \times 1000 /(7844.47 \times 1000)$ $=313.5 \mathrm{MPa}<355 \mathrm{MPa}$

while for the full iteration,

$\sigma_{\max }=1000 \times 1000 /(30762.2)+2000 \times 1000 \times 1000 /(7374.97 \times 1000)$ $=303.5 \mathrm{MPa}<355 \mathrm{MPa}$

Again, the simplified method overestimated $W_{\text {eff }}$ but underestimated $A_{\text {eff }}$ so that the resistance estimation is still conservative.

\section{Box 7}

Detailed calculation steps of first two iterations for Example 5

1st iteration

Initial stress (assuming section is fully effective)

Stress at top of webs:

$1000 \times 1000 / 39600+2000 \times 1000 \times 1000 \times 490 / 646932 \times 10000=176.74 \mathrm{MPa}$

Stress at bottom of webs:

$1000 \times 1000 / 39600-2000 \times 1000 \times 1000 \times 490 / 646932 \times 10000=-126.23 \mathrm{MPa}$
Effective width of top flange

The top flange is clearly Class 4 and remains Class 4 in all subsequent iterations so that

$b_{e f f}=0.423 \times 980=414.5 \mathrm{~mm}, b_{e l}=0.5 \times 414.5=207.25 \mathrm{~mm}$,

$b_{e 2}=0.5 \times 414.5=207.25 \mathrm{~mm}$

Effective width of webs and section effective area

$\psi=-126.23 / 176.74=-0.714$

Hence, $42 \varepsilon /(0.67+0.33 \psi)=78.71<h_{w} / t_{w}=98$ and therefore the webs are again Class 4.

Stress ratio: $\psi=-0.714, k_{\sigma}=7.81-6.29 \psi+9.78 \psi^{2}=17.29, \bar{\lambda}_{p}=1.019$,

$\rho=0.860$

$b_{e f f}=0.860 \times(980 / 2)=421.4 \mathrm{~mm}, b_{e l}=0.4 \times 421.4=168.56 \mathrm{~mm}$,

$b_{e 2}=0.6 \times 421.4=252.84 \mathrm{~mm}$

$x=980 / 2-421.4=68.6 \mathrm{~mm}$.

Hence, $A_{\text {eff }}=A_{\text {gross }}-565.5 \times 10-2 \times 10 \times 68.6=32573 \mathrm{~mm}^{2}$

$I_{\text {eff }}$ and $W_{\text {eff }}$ calculations

Shift of centroid: $\Delta G=-98.03 \mathrm{~mm}$

$I_{\text {eff }}=465696.55 \mathrm{~cm}^{4}, W_{\text {eff }}=465696.55 \times 10 /(495+98.03)=7852.83 \mathrm{~cm}^{3}$

Updated stress at webs

Compressive stress due to axial force: $1000 \times 1000 / 32573=30.7 \mathrm{MPa}$

Bending stress at top of webs:

$2000 \times 1000 \times 1000 \times(490+98.03) / 465696.55 \times 10000)=252.54 \mathrm{MPa}$

Bending stress at bottom of webs:

$-2000 \times 1000 \times 1000 \times(490-98.03) /(465696.55 \times 10000)=-168.34 \mathrm{MPa}$

Total stress at top of webs: $252.54+30.7=283.04 \mathrm{MPa}$ (compression)

Total stress at bottom of webs: $-168.34+30.7=-137.64 \mathrm{MPa}$ (tension)

\section{$\underline{2 n d \text { iteration }}$}

New stress ratio $\psi=-137.64 / 283.04=-0.486$

Effective width for webs and new $A_{\text {eff }}$

$k_{\sigma}=7.81-6.29 \psi+9.78 \psi^{2}=13.177, \bar{\lambda}_{p}=1.168, \rho=0.755$

$b_{e f f}=0.755 \times(980 / 2+98.03)=443.96 \mathrm{~mm}, b_{e l}=0.4 \times 443.96=177.58 \mathrm{~mm}$,

$b_{e 2}=0.6 \times 443.96=266.38 \mathrm{~mm}$

$x=980 / 2+98.03-443.96=144.07 \mathrm{~mm}$,

$A_{\text {eff }}=A_{\text {gross }}-565.5 \times 10-2 \times 10 \times 144.96=31063.6 \mathrm{~mm}^{2}$

$I_{\text {eff }}$ and $W_{\text {eff }}$ calculation

Shift of centroid $\Delta G^{\prime}=-112.41 \mathrm{~mm}$

I.e. $\Delta G^{\prime}-\Delta G^{\prime \prime}=-98.03-(-112.41)=14.38 \mathrm{~mm}$ (downward)

$I_{\text {eff }}=451965.18 \mathrm{~cm}^{4}, W_{\text {eff }}=451965.18 \times 10 /(490+112.41+5)=7440.86 \mathrm{~cm}^{3}$

Updated stress at webs

Compressive stress due to axial force: $1000 \times 1000 / 31063.6=32.19 \mathrm{MPa}$

Bending stress at top of webs:

$2000 \times 1000 \times 1000 \times(490+112.41) /(451965.18 \times 10000)=266.57 \mathrm{MPa}$

Bending stress at bottom of webs:

$-2000 \times 1000 \times 1000 \times(490-112.41) /(451965.18 \times 10000)=-167.09 \mathrm{MPa}$

Total stress at top of webs: $266.57+32.19=298.76 \mathrm{MPa}$ (compression)

Total stress at bottom of webs: $-167.09+32.19=-134.9 \mathrm{MPa}$ (tension)

The new stress ratio for next iteration is $\psi=-134.9 / 298.76=-0.442$

Table 4

Summary of Example 5

\begin{tabular}{cccccc}
\hline Iteration & $A_{\text {eff }}\left(\mathrm{mm}^{2}\right)$ & $I_{\text {eff }}\left(\mathrm{cm}^{4}\right)$ & $W_{\text {eff }}\left(\mathrm{cm}^{3}\right)$ & $\Delta G(\mathrm{~cm})$ & $\psi$ \\
\hline 0 (Gross) & 39600 & 646932 & 13069.33 & --- & -1.0 \\
1 & 32573 & 465696.55 & 7852.83 & 98.03 & -0.714 \\
2 & 31063.6 & 451965.18 & 7440.86 & 112.41 & -0.486 \\
3 & 30764.2 & 449659.07 & 7370.37 & 115.09 & -0.442 \\
4 (Full) & 30762.2 & 449872.97 & 7374.97 & 115.00 & -0.445 \\
Simplified & $16980^{*}$ & $466126.44^{\wedge}$ & $7844.47^{\wedge}$ & $99.21^{\wedge}$ & $-0.712^{\wedge}$ \\
\hline Full/Simplified & 1.81 & 0.97 & 0.94 & --- & -- \\
\hline \multicolumn{5}{c}{ *B considering $N_{E d}$ only, ${ }^{\wedge}$ By considering $M_{E d}$ only }
\end{tabular}

Since the values of $N_{E d}$ and $M_{E d}$ are known and their simultaneous actions do not cause the section to yield, one could employ alternative Equations. 6 and 7 to get a larger $\rho$ so that a less conservative section resistance could be obtained. The corresponding results obtained are summarized in Table 5. From Table 5, it can be seen that by using the alternative equations, the values of $A_{\text {eff }}$ and $W_{\text {eff }}$ are respectively increased by $5.8 \%$ and $7.6 \%$ when comparing with the original method. 
Table 5

Summary of Example 5 by using alternative value of $\rho$

\begin{tabular}{cccccc}
\hline Iteration & $A_{\text {eff }}\left(\mathrm{mm}^{2}\right)$ & $I_{\text {eff }}\left(\mathrm{cm}^{4}\right)$ & $W_{\text {eff }}\left(\mathrm{cm}^{3}\right)$ & $\begin{array}{c}\Delta G \\
(\mathrm{~cm})\end{array}$ & $\psi$ \\
\hline 0 (Gross) & 39600 & 646932 & 13069.33 & --- & -1.0 \\
1 & 33945 & 485284.56 & 8403.78 & 82.46 & -0.714 \\
2 & 33074.8 & 474994.33 & 8100.31 & 91.39 & -0.522 \\
3 & 32712.4 & 470995.57 & 7982.43 & 95.04 & -0.5 \\
4 (Alterative) & 32564.4 & 469407.75 & 7935.62 & 96.52 & -0.492 \\
Full & 30762.2 & 449872.97 & 7374.97 & 115.00 & -0.445 \\
Simplified & $16980^{*}$ & $466126.44^{\wedge}$ & $7844.47^{\wedge}$ & $99.21^{\wedge}$ & $-0.712^{\wedge}$ \\
Alterative/Full & 1.059 & 1.043 & 1.076 & --- & --- \\
\hline Alterative/ & 1.92 & 1.01 & 1.01 & --- & --- \\
Simplified & & & & & \\
\hline
\end{tabular}

\section{Conclusions}

In this review, the basic principle adopted by EC3 for the calculation of Class 4 slender thin-walled steel section properties is summarized. A detailed discussion is given for the EC3's effective width method for section properties calculation. A summary of the effective width calculation steps for Class 4 plate element are given. Summary charts for the variations of effective width for internal and external plate elements under different direct stress ratio are also presented. For the calculation of section properties of Class 4 slender sections, both the full iteration procedure and the simplified procedure suggested by EC3 are discussed and summarized. In order to demonstrate the actual calculation procedure for slender section subjected to different loading conditions, five practical calculation examples are given and both the full iteration and the simplified procedures are employed to obtain the section properties for comparison. The calculation results show that while the simplified procedure could reduce the number of iterations needed and does not require the ratios between the axial force and the bending moments applied, it is encouraged to use the full iteration procedure as in general it will lead to slightly higher sectional resistance.

\section{Appendix A: Elevation of stress ratio $\psi$}

From Sections 2.3 and 3.1, in order to compute the effective width (or area) of any arbitrary plate element 1-2 (Fig. A1), one must first obtain the direct stress ratio $\psi$ of the plate element. From Equation 9, the direct stress at the two ends 1 and 2 of the elements can be expressed as

$\sigma_{1}(y, z)=\frac{N_{E d}}{A_{e f f}}+\frac{\left(M_{y, E d}+N_{E d} \Delta z\right)}{I_{y, e f f}(\Delta y, \Delta z)} y_{1}+\frac{\left(M_{z, E d}+N_{E d} \Delta y\right)}{I_{z, e f f}(\Delta y, \Delta z)} z_{1}$

$\sigma_{2}(y, z)=\frac{N_{E d}}{A_{e f f}}+\frac{\left(M_{y, E d}+N_{E d} \Delta z\right)}{I_{y, e f f}(\Delta y, \Delta z)} y_{2}+\frac{\left(M_{z, E d}+N_{E d} \Delta y\right)}{I_{z, e f f}(\Delta y, \Delta z)} z_{2}$

where $\left(y_{1}, z_{1}\right)$ and $\left(y_{2}, z_{2}\right)$ are the coordinates of ends 1 and 2, respectively. Assume that $\sigma_{2}<\sigma_{1}$, the stress ratio $\psi$ can be expressed as

$\psi=\frac{\sigma_{2}}{\sigma_{1}}=\frac{\frac{N_{E d}}{A_{e f f}}+\frac{\left(M_{y, E d}+N_{E d} \Delta z\right)}{I_{y, e f f}(\Delta y, \Delta z)} y_{2}+\frac{\left(M_{z, E d}+N_{E d} \Delta y\right)}{I_{z, e f f}(\Delta y, \Delta z)} z_{2}}{\frac{N_{E d}}{A_{e f f}}+\frac{\left(M_{y, E d}+N_{E d} \Delta z\right)}{I_{y, e f f}(\Delta y, \Delta z)} y_{1}+\frac{\left(M_{z, E d}+N_{E d} \Delta y\right)}{I_{z, e f f}(\Delta y, \Delta z)} z_{1}}$

or

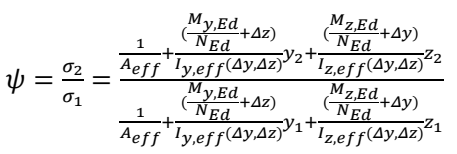

Hence, only the values of the ratios $\frac{M_{y, E d}}{N_{E d}}$ and $\frac{M_{z, E d}}{N_{E d}}$ are needed for the calculation of $\psi$ and then the evaluation of the effective section properties.

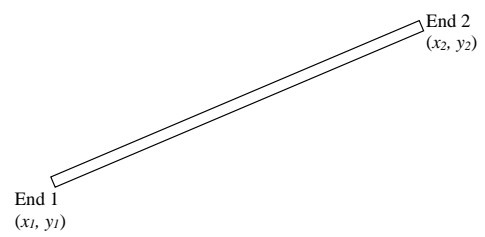

Fig. A1 Stress ratio calculation for a straight plate element 1-2

\section{References}

[1] British Standard Institution, Eurocode 3: Design of Steel Structures: Part 1-1 General rule and rules for buildings, BS EN 1993-1-1, BSI London, 2005.

[2] British Standard Institution, Eurocode 3: Design of Steel Structures: Part 1-5 Plated Structural elements, BS EN 1993-1-5, BSI London, 2006.

[3] Gardner L. and Nethercot D.A., "Designer's guide to Eurocode 3: Design of steel buildings EN 1993-1-1, -1-3 and -1-8", Second edition, ICE publishing, 2011.

[4] Beg D., Kuhlmann, U., Davaine L. and Braun, B., "Design of plated Structures Eurocode 3: Design of steel structures: Part 1-5- Design of plated structures", ECCS and Ernst \& Sohn, 2010 .

[5] Timoshenko S.P and Gere J.M., Theory of Elastic Stability, McGraw Hill Book Company, International Edition, 1963.

[6] Lee C.K. and Chiew S.P., "An efficient modified flanges only method for plate girder bending resistance calculation", Journal of Constructional Steel Research, 89, 98-106, 2013

[7] Gardner L. and Chan T.M., "Cross-section classification of elliptical hollow sections", Steel and Composite Structures, 7(3), 185-200, 2007.

[8] Prachar M., Hricak J., Jandera M., Wald F., Zhao B., "Experiments of Class 4 Open section beams at elevated temperature", Thin-Walled Structures, 98, 2-18, 2016. 